DOI: https://doi.org/10.47405/mjssh.v6i12.1199

\begin{tabular}{|c|c|}
\hline 4.581 & Malaysian Journal of Social Sciences and Humanities (MJSSH) \\
\hline $\begin{array}{l}\text { Malaysian Journal of } \\
\text { socal s ciences and }\end{array}$ & Volume 6, Issue 12, December 2021 \\
\hline (MJ-SSH) & e-ISSN : 2504-8562 \\
\hline & $\begin{array}{l}\text { Journal home page: } \\
\text { www.msocialsciences.com }\end{array}$ \\
\hline
\end{tabular}

\title{
Persepsi Ibu Bapa Orang Asli Terhadap Pengalaman Pendidikan Anak-anak Orang Asli di Sekolah
}

\author{
Yew Wong Chin ${ }^{1}$, Saiful Farisin Md Ramlan ${ }^{1}$, Mohd Rusydi Ahmad ${ }^{1}$, Norhayati Ab Manaf², \\ Novel Lyndon', Lim Jie Wei ${ }^{1}$ \\ ${ }_{1}^{1}$ Pusat Kajian Pembangunan, Sosial dan Persekitaran, Fakulti Sains Sosial dan Kemanusiaan, Universiti \\ Kebangsaan Malaysia (UKM), Malaysia \\ 2Institute of Tropical Biodiversity and Sustainable Development, Universiti Malaysia Terengganu (UMT), \\ Malaysia
}

Correspondence: Yew Wong Chin (email: vivienyew@ukm.edu.my)

\begin{abstract}
Abstrak
Bidang formal yang terbaik adalah bidang pendidikan yang berupaya untuk meningkatkan kualiti dan kesejahteraan hidup melalui pembangunan diri seterusnya mencorakkan masa hadapan individu itu sendiri. Justeru, sistem pendidikan yang mapan mampu untuk menarik minat anak-anak Orang Asli untuk meneruskan proses pembelajaran awal mereka di sekolah rendah. Walaupun Kementerian Pendidikan Malaysia telah mengeluarkan panduan silibus 3M (membaca, mengira, menulis) untuk membasmi masalah keciciran literasi dan numerasi, namun silibus tersebut masih tidak berjaya mengurangkan masalah penguasaan dan keciciran pembelajaran dalam kalangan murid-murid Orang Asli di Sekolah Kebangsaan Sungai Berua. Makalah ini merupakan kajian kualitatif bagi melihat kaedah dan inisiatif pengajaran dan pembelajaran yang diterapkan oleh guru dan pihak Sekolah Kebangsaan Sungai Berua dalam proses pembelajaran anak-anak Orang Asli Sungai Berua. Bagi mencapai tujuan tersebut, sesi temu bual telah dijalankan bersama ibu bapa Orang Asli dan guru-guru Sekolah Kebangsaan Sungai Berua untuk mengenal pasti inisiatif guru dan pihak sekolah serta persepsi ibu bapa dalam menguruskan proses pengajaran dan pembelajaran murid-murid Orang Asli. Hasil Kajian mendapati terdapat tiga inisiatif utama dalam proses pengajaran kepada murid-murid Orang Asli iaitu kesejahteraan pelajar (well-being), penglibatan ibu bapa (participation), dan pencapaian (achievement). Justeru, kaedah pengajaran bersertakan elemen kebudayaan Orang Asli turut digunakan untuk mengurangkan masalah literasi dan keciciran pembelajaran dalam kalangan murid-murid. Namun begitu, pihak guru dan sekolah juga berdepan dengan cabaran untuk mewujudkan persekitaran pendidikan yang mapan seperti budaya dan sikap murid, peranan penyertaan ibu bapa serta kekurangan kemudahan bantu mengajar. Kerjasama yang holistik perlu dilakukan agar masalah literasi dan keciciran pendidikan dalam kalangan anak-anak Orang Asli dapat dikurangkan.
\end{abstract}

Kata kunci: kemapanan, pendidikan, Orang Asli, pembelajaran, pendidikan formal, pengajaran

\section{Perceptions of Indigenous Parents on Indigenous Children's Experiences in School}

\begin{abstract}
In a developing nation, education is the best platform for its people to improve their quality of life and wellbeing. This is especially relevant to Orang Asli communities who are usually marginalized. Hence, an education system that can attract and retain Orang Asli children in primary school is vital to
\end{abstract}


improving the social mobility of Orang Asli communities in Peninsular Malaysia. The Ministry of Education Malaysia had introduced 3M syllabus (reading, writing, and counting) to eradicate illiteracy through reduction of dropouts amongst Orang Asli children. Nevertheless, the implementation of the 3M syllabus has not seen the desirable result amongst the Orang Asli pupils at the Sekolah Kebangsaan Sungai Berua, Terengganu. This qualitative study aims to analyze the three important aspects that have positive and negative impacts on the dropouts' issues as well as the achievement of Orang Asli children. They are (a) teachers' initiatives to incorporate Orang Asli cultural elements into the 3M syllabus and safeguarding wellbeing of Orang Asli children; (b) participation of Orang Asli parents at school; and (c) parents' attitudes towards education. Whilst the authors view positively the school and teachers' initiatives, a holistic collaboration to minimize the negative impact of the other two aspects is much anticipated to attain the final objective of reducing the dropout rates amongst Orang Asli children. Also, with additional teaching aids provided to the school and the teachers, the positive impact could be further enhanced.

Keywords: sustainability, education, Orang Asli, learning, formal education, teaching

\section{Pengenalan}

Secara umumnya di peringkat antarabangsa, tiada satu definisi umum yang digunakan untuk merujuk kepada masyarakat peribumi. Namun secara akademik, masyarakat peribumi merujuk kepada komuniti minoriti yang memiliki budaya tersendiri yang berkisarkan alam semula jadi selain cara hidup mereka yang berbeza dari segi sosial, budaya dan linguistik dari kumpulan masyarakat yang dominan. Terdapat sekitar 370-500 juta populasi masyarakat peribumi di seluruh dunia yang tersebar di 90 buah negara. Petempatan mereka berada di hampir semua kawasan geografi selain mewakili 5,000 budaya yang berbeza. Walaupun masyarakat peribumi hanya membentuk sekitar 5\% daripada keseluruhan populasi global, namun populasi ini juga menyumbang sekitar 15\% dalam kategori golongan miskin tegar di seluruh dunia, selain secara konsisten muncul di kedudukan paling bawah dalam penilaian keseluruhan kesejahteraan penduduk (Program Pembangunan Pertubuhan Bangsa-Bangsa Bersatu, 2019).

Salah satu punca utama kelemahan dan peminggiran berterusan ini adalah kualiti pendidikan yang tidak sesuai dengan hak mereka sebagai masyarakat peribumi seperti kurangnya kualiti pendidikan yang baik, sensitiviti budaya, pendidikan yang selaras dengan keperluan pembelajaran, kesesuaian bahasa, keutamaan dan aspirasi pendidikan selain penyampaian pendidikan melalui strategi pengajaran dan pembelajaran yang sesuai dengan budaya persekitaran.

Kajian Pertubuhan Bangsa-Bangsa Bersatu (PBB) pada tahun 2009 mengenai cabaran hak pendidikan masyarakat peribumi telah mengenal pasti beberapa halangan dan kebimbangan berat untuk merealisasikan hak pendidikan ke atas masyarakat peribumi (Pertubuhan Bangsa-Bangsa Bersatu, 2009). Kajian tersebut mendapati bahawa komuniti peribumi merasakan kurangnya kawalan ke atas inisiatif pendidikan yang memfokuskan kepada anak-anak peribumi. Malah, komuniti peribumi juga tidak dirujuk untuk memberikan pandangan terhadap program dan perkhidmatan pendidikan yang sedang dirancang dan dilaksanakan. Akibatnya, mereka mendapati bahawa program pendidikan yang dilaksanakan tidak disampaikan oleh kelompok peribumi itu sendiri selain tidak tersedia dalam bahasa komuniti dan tidak menghormati sejarah, pengetahuan tradisional serta budaya masyarakat peribumi (Pertubuhan Bangsa-Bangsa Bersatu, 2009).

Laporan PBB pada tahun 2009 juga menunjukkan bahawa pelan rancangan program pendidikan untuk anak-anak masyarakat peribumi di seluruh dunia, terutamanya terhadap golongan wanita dan anak-anak perempuan, haruslah memperakui dan mempertimbangkan keperluan khusus mereka dan halangan yang mereka hadapi untuk mendapatkan akses pendidikan yang berkualiti. Laporan PBB tersebut juga menjelaskan mengapa murid-murid peribumi tidak boleh dipaksa masuk untuk menerima sistem pendidikan arus perdana yang tidak menggabungkan budaya komuniti mereka selain mengguna pakai satu model pendidikan untuk semua murid-murid tanpa mengira latar belakang mereka seterusnya tidak 
memberi kesan buruk terhadap hak asasi mereka sebagai masyarakat peribumi (Pertubuhan BangsaBangsa Bersatu, 2009).

Manakala, Agenda Pembangunan Mapan 2030 turut merangkumi pertimbangan yang jelas terhadap masyarakat peribumi selain memberikan perhatian khusus kepada pendidikan mereka. Matlamat Pembangunan Mapan keempat (4) (SDG4) memfokuskan kepada pendidikan inklusif dan berkualiti untuk semua selain menggalakkan pembelajaran sepanjang hayat. Sekiranya matlamat keempat (4) ini dapat dicapai, matlamat ini diperlukan untuk memastikan akses pendidikan yang sama untuk anak-anak masyarakat peribumi, termasukkan bagi kanak-kanak kelainan upaya (OKU).

Seterusnya, Laporan PBB (2017) terhadap Pendidikan Peribumi turut menjelaskan bahawa pendidikan formal bagi masyarakat peribumi sering dianggap sebagai bentuk asimilasi mereka ke dalam masyarakat arus perdana. Misalnya, terdapat kes-kes buruk di luar jangkaan yang memperlihatkan keseluruhan komuniti mengalami penghapusan secara paksaan terhadap identiti anak-anak peribumi selain paksaan masuk ke dalam sekolah berasrama yang menyebabkan berlakunya penyalahgunaan dan penderaan kanak-kanak masyarakat peribumi. Namun, transformasi pendidikan daripada instrumen berasaskan asimilasi dan integrasi ke arah penentuan sendiri merupakan proses multidimensi jangka panjang yang kompleks. Kemajuan proses tersebut juga bergantung kepada keadaan serantau, negara dan masyarakat peribumi berkenaan (Pertubuhan Bangsa-Bangsa Bersatu, 2017).

Sistem pendidikan di Malaysia kini telah semakin berkembang seiring dengan kepesatan pembangunan negara. Pelbagai usaha telah diusahakan oleh pihak kerajaan melalui Kementerian Pendidikan Malaysia bagi membangunkan sokongan pendidikan kepada masyarakat Orang Asli agar bergerak seiring dengan kelompok perdana. Arena pendidikan negara terus berkembang melalui pelaksanaan pelbagai akta, dasar dan penyata seperti Dasar Pendidikan Negara, Laporan Razak 1956, Laporan Rahman Talib 1960 dan Pelan Pembangunan Pendidikan Malaysia.

Masyarakat Orang Asli tidak terkecuali dalam agenda pendidikan negara. Pendidikan bukan hanya semata-mata untuk mengenal huruf, membaca dan mengira. Namun kualiti pendidikan yang baik mampu membawa masyarakat Orang Asli meningkatkan kualiti dan kesejahteraan hidup. Keciciran penyertaan mereka dalam sistem pendidikan boleh menyebabkan kesukaran kepada anak-anak Orang Asli apabila meningkat dewasa kelak.

Pembangunan sistem pendidikan telah dilaksanakan di Malaysia adalah bertujuan melahirkan modal insan yang mampu berhadapan dengan cabaran era globalisasi akan datang. Kepantasan arus globalisasi adalah kesan daripada kepantasan teknologi dan jaringan maklumat telah memberi impak yang besar ke atas sistem pendidikan pada peringkat rendah, menengah dan tinggi. Ishak dan Nor Asikin (2003) menyatakan bahawa peluang pendidikan harus disediakan seluas-luasnya kepada kanak-kanak agar mereka dapat memiliki akses pendidikan asas yang terbaik untuk perkembangan pendidikan mereka seterusnya. Justeru, kualiti pendidikan yang mapan mampu untuk meningkatkan kualiti dalam proses pengajaran dan pembelajaran anak-anak Orang Asli.

Berdasarkan keterangan sejarah, Orang Asli diiktiraf sebagai komuniti yang terawal berada di negara ini. Walaupun mereka menjadi komuniti yang terawal berada di negara ini, tetapi tahap pencapaian mereka dalam aspek pendidikan dan pekerjaan amat mengecewakan berbanding kaum-kaum lain yang terdapat di Malaysia (Mohd Muizzuddin et al., 2018). Kajian oleh Wan et al. (2014) mendapati bahawa kebanyakan sekolah Orang Asli berada dalam ruang lingkup komuniti Orang Asli sahaja dan tiada campuran atau pergaulan dengan komuniti-komuniti lain. Justeru, keadaan ini juga merupakan antara salah satu faktor yang mempengaruhi kepada gaya pembelajaran murid-murid Orang Asli yang mana jika dilihat tiada berlaku persaingan atau cabaran dalam pembelajaran. Suasana pembelajaran tidak begitu mencabar dan persaingan untuk berada atau menyerlah dalam pembelajaran mahupun berada di tempat teratas adalah kurang. Wan et al. (2014) mendapati proses pembelajaran bagi murid-murid Orang Asli hanyalah sebagai memenuhi tuntutan kehidupan yang ditetapkan oleh kerajaan dan bukanlah satu matlamat yang penting bagi menjamin masa depan mereka dan sikap itulah yang menyebabkan anak-anak Orang Asli tidak berminat untuk pergi bersekolah. 
Walaupun Kementerian Pelajaran Malaysia telah mewajibkan pendidikan sekolah rendah melalui Akta Pendidikan Wajib dan Percuma 2013 (pindaan Akta Pelajaran 1996) kepada seluruh kelompok masyarakat, namun masih tidak banyak perubahan dari segi kehadiran dalam kalangan kanak-kanak Orang Asli ke sekolah (Suruhanjaya Hak Asasi Manusia 2010). Selain itu, penguasaan kemahiran 3M (membaca, menulis dan mengira) dalam kalangan murid-murid Orang Asli juga tidak memberangsangkan. Kajian yang dijalankan oleh Johari dan Nazri (2008) terhadap murid-murid Orang Asli suku Temuan di Jelebu, Negeri Sembilan mendapati bahawa hampir 90 peratus daripada mereka gagal menguasai kemahiran asas 3M walau sudah berada dalam tahun enam. Sedangkan sekolah tempat mereka belajar adalah sekolah kebangsaan yang mempunyai kemudahan asas yang hampir sama dengan sekolah-sekolah masyarakat perdana yang lain.

Menyedari hakikat ini, Kementerian Pelajaran Malaysia pada tahun 2006 telah memberikan arahan kepada semua 27 buah Institut Perguruan Malaysia di seluruh negara supaya membangunkan sekurangkurangnya sebuah sekolah rendah yang majoriti muridnya adalah keturunan Orang Asli (Johari \& Nazri, 2007). Makalah ini bertujuan untuk menjelaskan kemapanan proses pengajaran dan pembelajaran terhadap anak-anak Orang Asli di Perkampungan Orang Asli Sungai Berua, Terengganu. Persepsi ibu bapa komuniti Orang Asli diambil kira untuk melihat perkembangan proses pengajaran dan pembelajaran di sekolah yang telah mengubah penglibatan ibu bapa Orang Asli terhadap pendidikan anak-anak mereka.

\section{Kajian Literatur}

Terdapat pelbagai definisi, tafsiran dan perdebatan mengenai konsep kemapanan pendidikan yang digunakan dalam sesebuah kajian. Menurut Van den Branden (2015) melalui tafsiran dan kajian literatur tentang kedua-dua konsep tersebut, definisi operasional diberikan kepada setiap konsep yang berasingan serta cara bagaimana ianya digunakan adalah bergantung kepada objektif penyelidikan dan konteks sesebuah kajian. Dalam kajian ini, hanya konsep kemapanan pendidikan anak-anak masyarakat Orang Asli peringkat sekolah rendah sahaja diberi tinjauan yang jelas.

Mohd Muizzuddin et al. (2018) dalam kajian mereka tentang kesedaran pendidikan dan minat kerja pelajar Orang Asli suku Jakun di Rompin, Pahang mendedahkan bahawa terdapat pelbagai faktor yang menyebabkan pendidikan menjadi pilihan utama kepada masyarakat Orang Asli untuk kerjaya masa depan mereka. Kajian tersebut juga berjaya mengikis pandangan negatif yang melihat mentaliti Orang Asli masih di takuk lama kerana tidak mengutamakan pendidikan serta kerjaya sebagai medium untuk memajukan diri dan keluarga. Malah, pelajar Orang Asli suku kaum Jakun di kawasan kajian juga dapat menyesuaikan diri dalam proses sosialisasi formal melalui proses pembelajaran di sekolah. Keadaan ini dipengaruhi oleh pelbagai faktor antaranya ialah keluarga, jarak sekolah yang berhampiran, kemudahan pengangkutan, peranan guru, rakan sebaya dan faktor kemudahan pembelajaran di sekolah.

Manakala, kajian oleh Mohamad Johdi et al. (2009) di Sungai Berua mendapati bahawa kesedaran masyarakat Orang Asli terhadap pendidikan anak-anak mereka masih tidak berubah malah beranggapan bahawa walaupun tidak mempunyai pendidikan yang tinggi, kehidupan mereka masih lagi boleh diteruskan dan sikap mereka yang hanya menerima apa sahaja yang ada tanpa ada usaha untuk memajukan diri dan meningkatkan taraf hidup turut mempengaruhi mentaliti anak-anak Orang Asli untuk terus hidup dalam keadaan yang statik. Selain itu, faktor kedudukan perkampungan Orang Asli Sungai Berua yang jauh di pedalaman turut memberi kesan terhadap pendidikan anak-anak Orang Asli kerana kedudukan yang jauh terpencil memisahkan mereka dengan perkembangan teknologi dan kemudahan yang disediakan misalnya pengangkutan, perpustakaan dan alat perhubungan turut menyumbang kepada kebergantungan terhadap hasil hutan ataupun kehidupan yang berorientasikan hutan sahaja (Mohamad Johdi et al., 2009). Justeru, makalah ini turut tertarik dengan suasana pembelajaran murid-murid Orang Asli ini dalam mendapatkan akses pendidikan.

Malah, pendidikan juga dianggap salah satu sebagai bentuk kesejahteraan dan kualiti hidup masyarakat Orang Asli. Kajian yang dilakukan oleh Ross dan Willigen (1997) membincangkan pendidikan dan hubungannya dengan aspek kualiti hidup secara subjektif. Manakala, Yew et al. (2018) dalam kajiannya 
terhadap kesejahteraan masyarakat Orang Asli melihat kepada komponen-komponen kualiti hidup seperti kesihatan, infrastruktur, ekonomi dan pendidikan agar seiring dengan tahap kesejahteraan masyarakat perdana di Malaysia. Kualiti pendidikan yang diterima oleh masyarakat Orang Asli merupakan salah satu penunjuk sosial di dalam kualiti pembangunan sosial penduduk Malaysia. Wahab et al. (2013) dalam kajiannya memfokuskan kepada kualiti pendidikan anak-anak Orang Asli melalui pengenalan pendekatan pembelajaran luar bilik darjah dengan menggunakan elemen-elemen Sekolah Rimba Malaysia (eSRM) kepada murid-murid Orang Asli.

Rosniza et al. (2017) menjelaskan bahawa pendidikan masyarakat Orang Asli mempunyai hubung kait dengan lingkungan persekitaran tempat tinggal mereka. Kajian yang dijalankan di Muadzam Shah, Pahang mendedahkan bahawa ibu bapa merupakan faktor terbesar yang menyumbang kepada masalah literasi dalam kalangan anak-anak Orang Asli. Johari dan Nazri (2007) menjelaskan bahawa persekitaran yang kurang menggalakkan perkembangan kanak-kanak memberi kesan kepada perkembangan tingkah-laku kanak-kanak yang seterusnya memberi kesan kepada pencapaian akademik. Selain itu, masalah literasi dalam kalangan ibu bapa dan kurangnya kesedaran tentang kepentingan pendidikan mendorong mereka untuk menyerahkan sepenuhnya tanggungjawab mendidik anak-anak kepada pihak sekolah. Masalah literasi dan keciciran pendidikan dalam kalangan anak-anak Orang Asli juga dibantutkan akibat faktor kemiskinan keluarga. Kemiskinan menyebabkan ibu bapa tidak dapat menyediakan kualiti pendidikan yang terbaik dari rumah untuk anak-anak mereka (Siti Masayu \& Narimah, 2018). Malah, Ogburn (1964) menjelaskan bahawa pembangunan keluarga mempunyai hubungan rapat dengan pendidikan awal kanak-kanak. Kesejahteraan hidup keluarga yang kurang memberangsangkan menyebabkan ibu-bapa mengabaikan pendidikan anak-anak sebagai keutamaan utama.

Pendidikan awal anak-anak Orang Asli memainkan peranan yang sangat penting dalam perkembangan pembelajaran mereka. Namun, bukan semua anak-anak Orang Asli dapat menerima dengan mudah dengan silibus pembelajaran kurikulum yang disediakan oleh pihak kementerian pendidikan. Kerajaan melalui kerangka Pelan Pembangunan Pendidikan Malaysia (PPPM) 2013 hingga 2025 menjadi dasar untuk memberi peluang kepada murid orang asli dan kumpulan minoriti peribumi di Sarawak dan Sabah untuk menikmati peluang yang sama seperti murid arus perdana yang lain bagi menjamin keberhasilan akses pendidikan berkualiti dan bertaraf antarabangsa (Celinea \& Zamri, 2018). Kementerian Pendidikan Malaysia telah mengambil langkah dengan memperkenalkan silibus kurikulum khas yang digubal mengikut kesesuaian tahap kognitif dan kemampuan anak-anak Orang Asli dengan melibatkan elemen budaya dalam konteks masyarakat Orang Asli itu sendiri (Norwaliza \& Ramlee, 2015). Kurikulum Orang Asli dan Penan (KAP) merupakan program kurikulum pembelajaran awal kanakkanak yang bertujuan untuk meningkatkan kadar penguasaan 3M dalam kalangan murid-murid Orang Asli (Ainol Hamidah \& Saemah, 2018).

Namun begitu, masalah keciciran literasi dan perkembangan pendidikan dalam kalangan anak-anak Orang Asli adalah amat membimbangkan (Johari \& Nazri, 2007). Kajian Nazariyah (2014) berkaitan jurang literasi murid-murid Orang Asli turut mendapati faktor persekitaran kehidupan murid-murid Orang Asli merupakan antara cabaran yang dihadapi oleh murid-murid Orang Asli tidak menguasai literasi sekali gus mempengaruhi pembelajaran mereka. Kajian tersebut juga mendapati bahawa gangguan dalam persekitaran murid-murid Orang Asli seperti kekurangan kemudahan pengangkutan dan ketidakselesaan ruang belajar merupakan antara faktor yang mempengaruhi pembelajaran mereka (Nazariyah, 2014). Keadaan persekitaran tersebut menyebabkan kognitif pembelajaran murid-murid Orang Asli tidak dapat dirangsang malahan menyukarkan proses pembelajaran.

Justeru, bagi mengatasi masalah literasi tersebut, kementerian pendidikan telah memperkenalkan program LINUS untuk membasmi masalah keciciran literasi dalam kalangan murid-murid sekolah rendah. Abdul Jalil et al. (2011) menjelaskan program LINUS telah diperkenalkan sejak tahun 2010 merupakan sebuah program pendidikan yang memberi peluang pembelajaran yang lebih luas kepada murid-murid di sekolah rendah yang keciciran dalam penguasaan $3 \mathrm{M}$ iaitu membaca, menulis dan mengira. Maszuraini et al. (2012) menambah, LINUS (Literacy and Numeracy Screening) merupakan sebuah program pemulihan di bawah NKRA (National Key Result Area) pendidikan yang direka bentuk untuk memastikan murid yang mempunyai kesukaran untuk menguasai kemahiran asas literasi dan 
numerasi dapat mencapai standard penguasaan kemahiran asas yang kukuh pada tiga tahun pertama persekolahan.

Terdapat juga pelan pendidikan seumpama Kurikulum Orang Asli dan Penan (KAP) di Malaysia yang direka bentuk untuk golongan pelajar dan masyarakat asal (first nation), Orang Asal (aboriginal) dan Orang Asli (native) di beberapa negara seperti Kanada, Australia dan New Zealand. National Collaborating Center for Aboriginal Health (2017) menjelaskan, kerajaan Kanada telah merangka dasar kurikulum khas untuk golongan pelajar masyarakat asal (first nation), Puak Inuit dan Puak Meitis yang dikenali sebagai Early Childhood Education and Care (ECEC). Kurikulum ini bertujuan untuk memperdaya kelompok masyarakat asal Kanada untuk bersaing dengan masyarakat perdana yang lain dengan melibatkan empat teras utama iaitu kesejahteraan pelajar (well-being), penglibatan (participation), penyertaan (engagement) dan pencapaian (achievement).

Manakala di Australia pula, dasar pendidikan di dalam National Aboriginal and Torres Strait Islander Education Strategy (2015) menjelaskan bahawa pelan pendidikan awal iaitu Australian Early Development Census (AEDC) dibentuk oleh Education Council untuk kelompok Aboriginal dan masyarakat Torres Strait Islander bagi membolehkan mereka mendapatkan peluang pendidikan berkualiti yang sama dengan kelompok arus perdana Australia seterusnya sebagai strategi masa hadapan untuk mereka bersaing di dalam dunia kerjaya (Education Council, 2015). Terdapat 3 kunci utama di dalam dasar tersebut, antaranya ialah kepimpinan (leadership), kualiti pengajaran (quality teaching), kerjasama budaya dan identiti (culture and identity and partnerships). Education Council (2015) menambah, 4 fokus utama juga dikenal pasti sebagai strategi pendidikan iaitu kesediaan sekolah dan pelajar (school and child readiness), literasi dan numerasi (literacy and numeracy), kehadiran (attendance) dan transisi selepas persekolahan tamat (transition points including pathways to postschool option).

\section{Kaedah Kajian}

Kajian ini menggunakan pendekatan secara kualitatif dalam proses pengumpulan data. Proses pengumpulan data dilakukan menerusi kerja lapangan melibatkan kawasan kajian yang terletak di Kampung Orang Asli Sungai Berua, Kuala Behrang, Terengganu. Data telah dikumpulkan pada bulan September 2018 dan dibincangkan berdasarkan maklumat tentang persepsi ibu bapa terhadap pendidikan dan pembelajaran murid-murid Orang Asli.

Sejumlah 16 orang informan terdiri daripada guru (2), Batin (1), ibu bapa (9), ustaz (1), murid-murid (3). Pemilihan informan adalah berdasarkan kriteria yang dikehendaki iaitu informan merupakan ibu bapa dan anak-anak di bawah umur 10 tahun di Kampung Orang Asli Sungai Berua. Bagi tujuan penyelidikan triangulasi, sesi temu bual juga turut dilakukan bersama Batin kampung, Ustaz dan Pegawai JAKOA Daerah. Pemilihan sampel adalah berdasarkan kepada pensampelan bertujuan (purposive sampling) melalui beberapa kriteria yang terdapat pada informan.

Selain itu, data juga diperoleh melalui pemerhatian secara langsung semasa kerja lapangan dijalankan. Pemerhatian dan temu bual dilakukan untuk mengenal pasti pelbagai kriteria pentafsiran kepada kualiti pendidikan murid-murid Orang Asli seperti kemudahan prasarana fizikal (bilik darjah), infrastruktur asas (jalan raya, utiliti elektrik dan air serta keperluan asas), ekonomi penduduk, (pekerjaan, aktiviti seharian) dan sosio-budaya terdapat di Kampung Orang Asli Sungai Berua. Seterusnya, data yang diperoleh direkodkan dalam bentuk nota lapangan sebelum disalin ke dalam bentuk transkripsi untuk dianalisis. Beberapa tema kajian terbentuk hasil daripada dapatan kajian ini.

\section{Kawasan Kajian}

Kampung Orang Asli Sungai Berua merupakan penempatan semula kampung Orang Asli yang dipindahkan dari lokasi hutan dan bukit berhampiran. Kampung ini dibuka pada tahun 1977 dan berkeluasan sekitar 84 hektar serta terletak di pendalaman daerah Hulu Terengganu. Namun, jarak kampung ini dengan pekan Kuala Berang ialah sekitar 13 kilometer. Kampung Orang Asli Sungai Berua 
juga berhampiran dengan Tasik Kenyir serta berhubungan dengan jalan utama iaitu jalan raya Kuala Berang-Tapah.

Rajah 1: Kedudukan lokasi Kampung Sungai Berua yang berhampiran dengan Tasik Kenyir

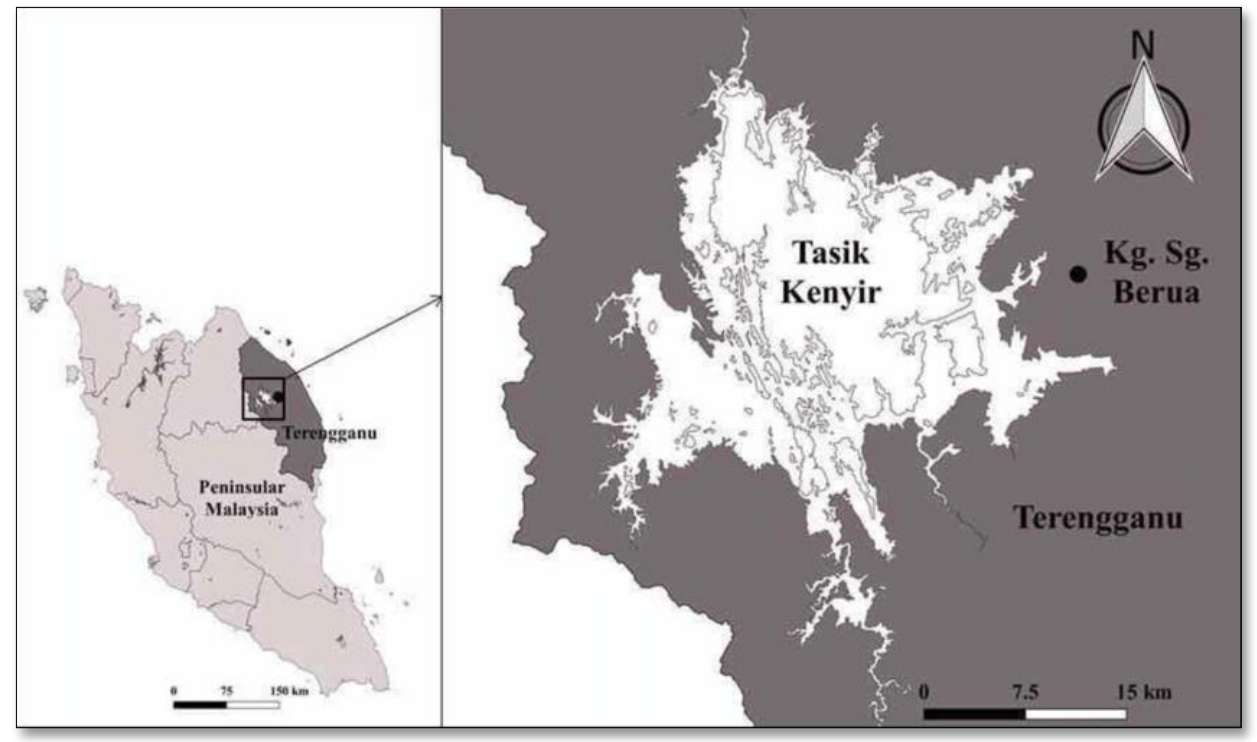

Sumber: Candyrilla Vera Bartholomew (2017)

Manakala, Sekolah Kebangsaan Sungai Berua terletak di dalam kawasan penempatan Kampung Orang Asli Sungai Berua. Sekolah Kebangsaan (OA) Sungai Berua telah ditubuhkan pada tahun 1974 yang dibangunkan oleh Jabatan Hal Ehwal Orang Asli (JHEOA). Pada tahun 1985, Sekolah Kebangsaan Sungai Berua telah diletakkan di bawah pengurusan pentadbiran Jabatan Pendidikan Negeri Terengganu (JPNT) bagi menyelaraskan struktur pentadbiran hal ehwal sekolah dan pelajar. Sekolah ini telah mengalami proses perubahan infrastruktur pendidikan yang kini dilengkapi dengan enam bilik darjah, bilik guru, makmal komputer, perpustakaan, kantin dan kawasan riadah. Sewaktu kerja lapangan dijalankan, Sekolah Kebangsaan Sungai Berua mempunyai 113 orang murid yang terdiri daripada 49 murid lelaki dan 64 murid perempuan di bawah bimbingan 15 orang tenaga pengajar.

Kampung Sungai Berua merupakan salah satu kampung tersusun masyarakat Orang Asli di bawah program Rancangan Pengumpulan Semula (RPS). Selain itu, petempatan mereka juga dilengkapi dengan pelbagai kemudahan prasarana dan utiliti asas seperti jalan kampung berturap, bekalan elektrik, bekalan air, lampu jalan, sistem perparitan terancang, kawasan riadah, generator pengepam air, dewan komuniti (atau 'balai raya'), sekolah rendah, taman asuhan kanak-kanak dan surau. Sebahagian besar rumah penduduk mempunyai bekalan elektrik yang disambungkan dari jana kuasa utama di kawasan di luar petempatan mereka. Hampir kesemua penduduk mempunyai akses kepada bekalan air bersih. Akses capaian telekomunikasi di sekitar kawasan kampung terutamanya sekolah adalah terhad. Malah, capaian sambungan Internet adalah amat mustahil di kawasan kampung ini. Penduduk terpaksa bergerak keluar dari kawasan kampung atau ke kawasan yang lebih tinggi untuk mendapatkan liputan telekomunikasi yang baik.

\section{Hasil Kajian dan Perbincangan}

\section{Inisiatif Pengurusan Sekolah}

Sekolah Kebangsaan Sungai Berua tidak mengamalkan sistem aliran kelas dan pengelasan murid seperti sekolah-sekolah biasa di peringkat aliran perdana yang lain. Pihak guru di SK Sungai Berua pula mempunyai jumlah murid yang kecil seterusnya membolehkan mereka untuk memberi tumpuan yang lebih kepada murid-murid. Malah, sesi pengajaran dan pembelajaran yang diterapkan oleh guru-guru SK 
Sungai Berua lebih tertumpu untuk memperkasa penguasaan kemahiran asas $3 \mathrm{M}$ seperti membaca, menulis dan mengira dalam kalangan murid-murid.

Walaupun pihak Kementerian Pendidikan Malaysia telah menyediakan silibus Kurikulum Asli dan Penan (KAP) sebagai sukatan pelajaran khas untuk murid-murid Orang Asli, namun silibus tersebut tidak dapat digunakan sepenuhnya sebagai sukatan pelajaran di SK Sungai Berua. Zalina (guru) menyatakan:

“...sekolah ni ada lebih kurang 113 orang murid... tahap mereka semua pun berlainan... ada yang tahu membaca, begitu jugak sebaliknya yang tak tahu membaca... dekat sini kebanyakan murid dapat memahami dan bercakap dalam bahasa Melayu dengan agak fasih, jadi senang cikgu-cikgu nak mengajar asas $3 M \ldots$.

Zalina (guru) menambah “...students saya memang tak boleh ikut silibus yang biasa iaitu KSSR kerana memang tahap pencapaian mereka tu memang kurang baik... jadi kita nak gunakan pendekatan yang sekolah lakukan sendiri untuk students... misalnya cara pengajaran kami lebih fleksibel, macam campurkan silibus pengajaran KAB dengan nyanyian, video... students pun jadi seronok nak belajar..."

Kenyataan tersebut jelas menunjukkan keupayaan pembelajaran yang masih lemah dalam kalangan murid-murid Orang Asli di Sekolah Kebangsaan Sungai Berua. Walaupun tujuan asal pembentukan silibus KAP adalah untuk meningkatkan kadar penguasaan 3M dalam kalangan murid-murid Orang Asli, namun pihak sekolah telah meneliti serta mengambil kira keupayaan pembelajaran yang berbeza dalam setiap orang murid. Zalina (guru) menjelaskan:

“...lebih kurang $10 \%$ je yang boleh membaca, tapi penguasaan membaca mereka tu pun pada tahap yang rendah lagi lah. Macam sekarang ni murid Tahun 5 dalam 2, 3 orang, tapi guna silibus tahun $3 . . . ”$

Noor (Ibu) menambah: “...anak saya dah masuk darjah 6, tapi dia masih lambat nak membaca, kalau huruf tu dia kenal, cuma kalau nak membaca tu dia lambat sikit, jauh beza masa dia darjah 4 dengan darjah 5, langsung tak pandai baca..."

Siti (guru) menjelaskan: “...walaupun murid itu pandai membaca, tapi penerimaan dia tu payah sikit, jadi kita gunakan silibus KAB yang tahun 3, walaupun dia dah tahun 5. Apa yang penting bagi pihak sekolah, kita nak bagi dia asas $3 M$ sahaja..."

Bagi pihak sekolah dan guru itu sendiri, penguasaan kemahiran dan asas $3 \mathrm{M}$ adalah memadai bagi murid-murid Orang Asli. Malah, guru-guru pula berhadapan dengan cabaran untuk mengesan masalah pembelajaran murid yang kurang berkemahiran dalam 3M.

Salimah (Ibu) menjelaskan: “... macam anak saya darjah 5 dekat sekolah, cikgu pun tak kira tahun kelas anak saya.. saya pun cuma nak tengok dia boleh membaca mengira... anak saya pun masih lemah membaca dengan mengira, jadi dia kena ambil pelajaran yang awal macam murid tahun $2 . . . "$

Justeru, bagi tujuan menarik minat dan galakan kepada murid-murid Orang Asli untuk datang ke sekolah, pihak sekolah telah menggabungkan suasana pembelajaran akademik di dalam kelas dengan aktiviti-aktiviti sampingan yang lebih santai. Sesi persekolahan dimulakan dengan sarapan bersamasama di kantin.

Mawar (ibu) menjelaskan: “...anak-anak setiap pagi dapat sarapan bila datang ke sekolah.. kadang-kadang kalau terlambat bangun, saya suruh jugak dia pergi 
sekolah, sebab dekat sekolah boleh mandi bersiap, lepas tu baru boleh mula belajar..."

Ahmad (murid) menambah: “...pagi-pagi kalau sampai sekolah, cikgu suruh terus pergi kantin sarapan... cikgu suruh basuh tangan dulu baru makan, dengan kawankawan makan sama-sama..."

Namun, tidak semua murid-murid Orang Asli yang akan hadir ke sekolah dalam keadaan yang terurus. Terdapat sebilangan kecil murid-murid yang tidak mandi dan menyiapkan diri untuk memulakan sesi persekolahan. Justeru pihak sekolah akan mengarahkan mereka untuk mandi di sudut khas kawasan sekolah untuk menyiapkan diri. Seterusnya, pelajar akan berkumpul dan sesi pembelajaran dimulakan dengan membaca ayat-ayat lazim di dalam Al-Quran. Sesi pengajaran dan pembelajaran di dalam kelas adalah bergantung dengan guru yang bertugas. Hal ini jelaskan oleh tenaga pengajar SK Sungai Berua kerana terdapat dalam kalangan murid yang kehilangan fokus dan tidak bermotivasi untuk meneruskan pembelajaran.

Siti (guru) menjelaskan: “...Tapi dalam masa sambung untuk subjek lain tu, kadang-kadang murid kita tu dah tak berminat dah untuk duduk diam dalam kelas, menulis pun.. tak minat dah... mereka mula hilang fokus..."

Nurul (murid) menambah: “... kalau pergi sekolah seronok, dapat jumpa kawan ramai, cikgu selalu ajak menyanyi dalam kelas, ada jugak cikgu bukak tv tengok cerita..."

Kebiasaannya, pihak guru akan memberi peluang kepada murid untuk berehat dengan menonton televisyen, menyanyi, berkaraoke dan membaca buku cerita. Inisiatif pihak guru dan sekolah dapat memastikan agar perkembangan murid-murid dapat dibangunkan secara menyeluruh dan bersepadu dari segala aspek iaitu jasmani, rohani, intelektual, emosi dan sosial bertepatan dengan Falsafah Pendidikan Kebangsaan (FPK) yang berhasrat melahirkan insan yang seimbang dari segi intelek, rohani, emosi dan jasmani. Ianya juga selari dengan program kurikulum Early Childhood Education and Care (ECEC) di Kanada yang bertujuan untuk memperdaya kelompok pelajar masyarakat asal (peribumi) Kanada untuk bersaing dengan masyarakat perdana yang lain dengan melibatkan empat teras utama pendidikan iaitu kesejahteraan pelajar (well-being), penglibatan (participation), penyertaan (engagement) dan pencapaian (achievement).

Menurut Siti (guru):“.. Kalau cikgu sekolah sini lebih gunakan pendekatan mengajar secara bermain... cara tu dapat beri peluang kepada murid-murid Orang Asli belajar menyelesaikan pelbagai bentuk permasalahan mudah macam kognitif, motor, sosial.. bentuk pengajaran ni dapat menyumbang kepada aspek perkembangan intelek murid-murid..."

Berdasarkan maklumat yang diperolehi sewaktu proses pemerhatian dan temu bual bersama guru, pendekatan yang digunakan semasa mengajar pelajar di sekolah ini adalah melalui konsep belajar melalui bermain dilihat menjadi keutamaan dalam proses pengajaran dan pembelajaran di Sekolah Kebangsaan Sungai Berua.

Zalina (guru) menyatakan: “...memang kita tak boleh rigid ikut yang macam silibus sekolah biasa guna. Murid-murid pun tak boleh ikut lagi, sebab tahap penerimaan tu berlainan.. agak sukar kerana perkembangan mereka agak perlahan.. cikgu-cikgu sini selalu fokus dekat pembacaan asas.. memang itu target kami, sekurang-kurangnya mesti kuasai asas membaca, kenal huruf ABC, asas suku kata perkataan.. baru boleh menulis...”

Siti (guru) menambah “....Kalau nak bandingkan, SK Sungai Berua ni dengan sekolah asli yang lain pun, saya rasa.. tak boleh lagi, mereka pun tak boleh ikut lagi silibus kebangsaan, especially kalau sekolah asli yang dekat pedalaman tu, 
sebab tahap penerimaan murid-murid tu memang payah sikit, bergantung jugak dekat kemampuan murid tu sendiri..."

Hal ini mendapati bahawa pendekatan mengajar secara bermain adalah sifat semula jadi kanak-kanak yang boleh dijadikan perantara dan membantu meningkatkan pembelajaran pelajar Orang Asli Sungai Berua ke tahap yang optimum. Kaedah permainan dianggap sebagai salah satu strategi instruksional yang efektif dalam pembelajaran terutamanya bagi generasi baru. Permainan boleh diintegrasikan dalam aktiviti pengajaran untuk meningkatkan minat dan motivasi kanak-kanak serta usaha untuk menyelesaikan sesuatu tugasan pembelajaran. Ini kerana pengajaran yang menggunakan kaedah permainan sebagai medium pengajaran akan menjadikan pelajar belajar dengan cepat dan mereka akan lebih seronok. Malah, kaedah bermain juga dapat mengelakkan rasa bosan dan menghilangkan rasa takut kanak-kanak terhadap mata pelajaran yang diajar

\section{Inisiatif Pengajaran dan Pembelajaran di luar Kokurikulum}

Berikutan daripada keupayaan penguasaan pembelajaran yang masih lemah dalam kalangan muridmurid Orang Asli Sungai Berua. Pihak sekolah telah menjalankan program 'Beh LINUS' sebagai tindak balas kepada tujuan LINUS untuk meningkatkan kadar penguasaan 3M dalam kalangan murid-murid. LINUS ialah program yang dilaksanakan oleh Kementerian Pendidikan Malaysia di sekolah rendah seluruh negara untuk meningkatkan tahap literasi dan numerasi murid-murid tahun 1 hingga 3. Kajian ini bertujuan untuk meninjau penilaian LINUS yang dilaksanakan sejak tahun 2010. Namun begitu, dasar ini telah ditamatkan pada awal tahun 2019 oleh Kementerian Pendidikan Malaysia bagi digantikan dasar pendidikan baru yang akan diperkenalkan tidak lama lagi. Bagi pihak sekolah, fungsi dan perlaksanaan yang diperkenalkan LINUS sebelum ini masih diteruskan dalam proses pembelajaran kokurikulum. Pendekatan tersebut juga dilaksanakan di Australia menerusi dasar pendidikan di dalam National Aboriginal and Torres Strait Islander Education Strategy (2015) yang menjelaskan bahawa strategi pelan pendidikan awal iaitu kesediaan sekolah dan pelajar (school and child readiness), literasi dan numerasi (literacy and numeracy), kehadiran (attendance) dan transisi selepas persekolahan tamat (transition points including pathways to postschool option) (Education Council, 2015). Penyeragaman pendekatan LINUS turut di aplikasi dan di adaptasi di luar aktiviti kokurikulum sebagai satu bentuk pendekatan yang baru pihak sekolah bagi melahirkan insan yang seimbang dari segi jasmani, emosi, rohani dan intelek. Zalina (guru) menjelaskan:

“...kan sekarang ni ada silibus LINUS, setiap tahun kita akan buat program untuk LINUS, LINUS ni directed daripada 3 M lah. Kita untuk tahun ni baru je habis buat program yang dipanggil "Beh LINUS". Maknanya "tak nak LINUS" lagi dah. Maksudnya everybody mesti dah pandai membaca walaupun asas..."

Kenyataan tersebut jelas menunjukkan bahawa pihak sekolah menyasarkan sekurang-kurangnya penguasaan $3 \mathrm{M}$ yang asas dalam kalangan murid-murid. Pihak sekolah menyasarkan murid-murid Orang Asli SK Sungai Berua sekurang-kurangnya menguasai asas 3M. 'Beh LINUS' membawa maksud 'tak nak lagi LINUS' di dalam bahasa Semoq Beri. Program 'Beh LINUS' tersebut juga turut diperkasakan lagi dengan inisiatif pihak sekolah dengan menggabungkan kesemua murid-murid Orang Asli berdasarkan kategori keupayaan dan kemahiran asas 3M. Hal ini bermakna, tiada murid yang dikelaskan mengikut kategori kelas darjah seperti sekolah aliran perdana yang lain.

Setiap orang murid akan diuji satu persatu melalui pra-ujian dengan mengambil kira keupayaan mereka untuk membaca, menulis dan mengira. Seterusnya murid-murid tersebut akan dikategorikan kepada empat kumpulan iaitu kumpulan A, B, C dan D. Sebagai contoh, kumpulan A adalah terdiri daripada murid-murid yang mempunyai kemahiran asas $3 \mathrm{M}$ yang baik, manakala kumpulan $\mathrm{D}$ merupakan kumpulan murid yang lemah dalam keupayaan pembelajaran mereka. Murid-murid yang ditempatkan di dalam kumpulan tersebut juga dinilai berdasarkan keupayaan mereka untuk menangkap dan memahami bentuk pengajaran dan pembelajaran yang di sampaikan oleh guru. Setiap kumpulan juga terdiri daripada pelbagai peringkat umur. Zalina (guru) menjelaskan: 
“...kita tak kira mereka tahun berapa, tapi kita tengok pencapaian murid. Ada murid yang Tahun 4, tapi huruf 'A' pun dia tak kenal. Jadi dia akan duduk dalam kelas kumpulan D. Semuanya murid akan dikumpulkan dan di test untuk tentukan mereka termasuk dalam kumpulan yang mana..."

Intan (ibu) menambah "...saya tengok anak-anak saya yang ke sekolah, dah dapat faham baca buku, jadilah.. sikit-sikit nanti mesti makin pandai, dulu masa-masa mula masuk sekolah, langsung tak tau baca, ambik masa jugak dia nak kenal huruf..."

Modul dan sukatan pengajaran dalam 'Beh LINUS' juga adalah berdasarkan inisiatif pihak guru dan sekolah sendiri. Modul yang digunakan mengambil kira kemahiran sedia ada murid sebelum pendekatan yang sesuai yang oleh digunakan ke atas murid tersebut. Setiap kelas kumpulan akan diselia oleh dua orang guru pemulihan. Sebagai contoh, murid yang lemah di dalam penguasaan pembelajaran mereka di dalam kumpulan D adalah terdiri daripada murid Tahun 1, Tahun 2 dan Tahun 3. Mereka akan dikumpulkan dan diselia secara langsung.

Fokus pertama yang diberikan oleh guru pemulihan adalah melalui modul membaca dengan mengambil kira keupayaan murid untuk mematahkan suku kata di dalam perkataan. Masalah utama yang dihadapi oleh anak-anak Orang Asli ialah kesukaran memahami Bahasa Melayu yang merupakan bahasa perantaraan di sekolah. Justeru, 'Beh LINUS' menjadi nilai tambah dalam pengayaan komunikasi di dalam Bahasa Melayu dalam kalangan anak-anak Semaq Beri.

Zima (ibu) menjelaskan: “...kalau dekat rumah, anak-anak cakap bahasa kita (Semoq beri), tapi kalau pergi sekolah semuanya kena cakap Melayu, belajar pun dalam Melayu, senang jugak tengok, anak-anak senang belajar sebab cepat faham cakap Melayu...”

Rosmina (murid): “...dekat sekolah cikgu selalu bagi kad ada yang huruf, lepas tu sambung-sambung sampai perkataan, kalau dapat buat nanti cikgu bagi gulagula..."

Begitu juga dengan modul matematik dan mengira. Murid-murid akan didedahkan dengan bentukbentuk asas pengiraan matematik asas yang mudah difahami oleh mereka. Namun, bagi pelajar Tahun 6 yang menduduki peperiksaan UPSR, mereka dikecualikan daripada mengikuti program 'Beh LINUS' selain modul sukatan pelajaran murid Tahun 6 adalah sama seperti sekolah aliran perdana yang lain. Hal ini bagi memastikan mereka tidak tercicir untuk mengejar sukatan pelajaran aliran perdana sebagai persediaan menghadapi peperiksaan UPSR.

\section{Inisiatif Guru dan Pengajar}

Pihak guru Sekolah Kebangsaan Sungai Berua telah membina satu pelan tindakan yang fleksibel bagi memastikan penguasaan pembelajaran mengikut tahap pelajar dalam menguasai sesuatu perkara. Penggunaan media elektronik seperti paparan siaran video melalui visual dan audio merupakan salah satu pendekatan yang diambil dalam penguasaan pembelajaran interaktif di dalam kelas. Selain itu, pembangunan dalam aspek psikomotor (kemahiran), kognitif (pengetahuan) dan afektif (sikap) turut diaplikasikan kepada murid-murid Orang Asli seiring dengan kurikulum pendidikan Malaysia yang menekankan peningkatan kompetensi murid dalam pembelajaran dan pengajaran. Malah, guru-guru di Sekolah Kebangsaan Sungai Berua juga menjalankan sesi pengajaran dengan murid-murid secara santai tetapi penuh pengisian pembelajaran. Kaedah ini dapat mengurangkan perasaan bosan selain menarik minat murid untuk terus bertahan dalam proses pembelajaran. Zalina (guru) menyatakan:

“...lepas tu sambung lagi belajar. Tapi dalam masa sambung tu, kadang-kadang murid kita tu dah tak berminat dah untuk duduk dalam kelas, menulis.. tak minat dah. Biasanya lepas rehat kita bagi dia tengok TV, menyanyi, karaoke pun ada..." 
DOI: https://doi.org/10.47405/mjssh.v6i12.1199

Lina (ibu) menambah: “...anak-anak saya suka pergi sekolah sebab cikgu je saja ajar membaca dan menulis, tapi ada jugak bagi masa anak-anak buat kerja lain macam menyanyi, tengok TV... anak-anak ada cakap, dia suka menari kalau cikgu pasang lagu-lagu yang sedap didengar..."

Justeru, kenyataan tersebut menjelaskan bahawa aktiviti selingan rehat semasa sesi pengajaran dilakukan agar murid tidak terlalu bosan di dalam kelas. Guru yang mengajar akan melakukan aktiviti selingan seperti menyanyi, menonton televisyen serta melakukan senaman ringan bersama-sama anakanak Orang Asli di dalam kelas.

Rosmina (murid) menjelaskan: “...saya boleh sikit sikit baca dengan tulis, dekat belakang dalam almari banyak buku.. kalau rehat kejap, selalu cikgu suruh baca dengan kawan... seronok kalau cikgu masuk ajar.. cikgu pun selalu suruh melukis, lepas tu warnakan cantik-cantik..."

Apa yang lebih penting ialah sikap positif murid itu sendiri untuk belajar tanpa ada unsur paksaan daripada pihak lain. Minat mereka untuk belajar telah ditanam dalam sanubari setiap murid bagi membolehkan mereka mengorak langkah untuk mula membaca dan menulis secara berperingkat. Lindholm-Leary (2011) dalam kajiannya tentang penguasaan bahasa di China, pembangunan literasi dan sikap murid di peringkat sekolah rendah tahap dua dan menengah adalah penting untuk menentukan kemajuan dan sikap pelajar dalam proses pengajaran dan pembelajaran. Begitu juga kajian Noorsham Muhamad et al. (2012) yang melibatkan 93 buah sekolah rendah Orang Asli di Semenanjung Malaysia mendapati bahawa guru dan pihak sekolah memainkan peranan yang sangat penting dalam mencorakkan perkembangan pendidikan awal anak-anak Orang Asli. Proses pengajaran yang diterapkan oleh pihak guru antaranya ialah melibatkan teknik pengajaran holistik yang dapat menarik anak-anak Orang Asli supaya berminat dengan dunia persekolahan. Tidak ketinggalan, terdapat guru-guru SK Sungai Berua yang secara sukarela mengeluarkan perbelanjaan mereka sendiri untuk membeli hadiah atau token untuk murid-murid di dalam kelas. Malah, hiasan keceriaan kelas dan persekitaran sekolah juga adalah hasil sumbangan guru-guru. Semuanya dilakukan untuk menarik minat anak-anak Orang Asli agar datang ke sekolah. Zalina (guru) menjelaskan:

“....Sistem token memang ada. Kita memang buat macam-macam program untuk tarik murid-murid datang ke sekolah. Pernah satu masa tu, kita ada bagi students yang hadir ke sekolah 3 ringgit sehari. Cukup satu bulan, kita panggil parents kita bagi duit tu. Sebagai galakkan lah untuk murid datang sekolah..."

Nurul (murid): “...kalau cikgu bagi soalan, cikgu sellau bagi gula-gula kalau kita dapat jawab, kalau tak dapat pun, cikgu bagi je..kalau habis sekolah, cikgu pun bagi makan aiskrim jugak...”

Hal tersebut menunjukkan bahawa guru-guru SK Sungai Berua menggunakan sumber sedia ada yang dimiliki oleh mereka untuk menarik perhatian dan minat murid-murid untuk datang ke sekolah. Secara tidak langsung jumlah kehadiran pelajar akan bertambah seterusnya proses pengajaran dapat disampaikan dengan mudah kepada murid-murid yang hadir.

\section{Cabaran Pengajaran dan Pembelajaran}

Tidak dinafikan cabaran yang dihadapi oleh murid Orang Asli Sungai Berua ini seperti ponteng sekolah, mudah putus asa, tiada semangat, mudah jemu, sensitif dan pemalu merupakan antara faktor yang menyebabkan mereka ketinggalan jauh dalam arus pendidikan negara. Namun begitu, usaha untuk menarik masyarakat Orang Asli ini agar sama-sama mendukung aspirasi pendidikan negara tidak boleh dipandang ringan dan wajar diberi perhatian. Melalui inisiatif yang dilakukan oleh pihak sekolah bagi mendekati golongan ini menggunakan pendekatan pendidikan yang menarik dan memenuhi keperluan mereka adalah satu bentuk keperluan wajib bagi meningkatkan kefahaman masyarakat Orang Asli mengenai kepentingan pendidikan. 


\section{Budaya dan sikap masyarakat Orang Asli}

Budaya dan sikap Orang Asli amat mempengaruhi keberkesanan pendidikan terhadap anak-anak Orang Asli. Kesejahteraan kualiti hidup yang rendah turut menyebabkan kanak-kanak merasa rendah diri, kemerosotan estim kendiri, atau apa sahaja berkaitan dengan kendiri. Hal ini menyebabkan lemahnya personaliti kanak-kanak itu sendiri seperti kurangnya keyakinan diri, tidak aktif di sekolah, pasif berbicara dengan guru dan kurang kemahiran kognitif dalam konteks pembelajaran dan tingkah-laku dalam bilik darjah yang semuanya boleh dikategorikan sebagai tingkah-laku learned helpless.

Batin menjelaskan: “...saya suka kalau budak-budak dekat kampung suka pergi sekolah, cikgu-cikgu pun baik nak tolong anak-anak pandai baca, kira semua...yang tak bagusnya ada anak-anak yang cuti ponteng tak datang sekolah..."

Malah, budaya ponteng tegar dalam kalangan murid-murid Orang Asli turut menyebabkan sebahagian besar mereka gagal mengusai kemahiran asas $3 \mathrm{M}$. Masalah ponteng menyebabkan gangguan dalam proses pembelajaran mereka sehingga menyukarkan mereka untuk memahami sukatan unit mata pelajaran seterusnya membantutkan keupayaan mereka untuk menguasai kemahiran asas 3M. Kajian oleh Noorsham Muhammad et al. (2012) turut mendapati sikap murid itu sendiri yang menentukan perkembangan pendidikan mereka di sekolah rendah. Kajian tersebut turut mendapati masalah ketidakhadiran atau ponteng yang berpanjangan menyebabkan keciciran selain pencapaian akademik yang rendah serta tidak memuaskan. Zalina (guru) menjelaskan:

“...kebanyakan ibu bapa bagi anak-anak pergi ke sekolah, tapi kadang-kadang murid itu sendiri yang tak nak datang sekolah..."

Limah (ibu) menjelaskan: “....kalau seminggu tu, bukan setiap hari anak-anak pergi sekolah, kalau pagi bangun tidur tu, saya kejutkan mereka pergi, tapi anakanak ikut perasaan dia, jadi saya pun tak boleh nak paksa, tapi esoknya mesti pergi ke sekolah, tak boleh cuti banyak-banyak..."

Nani (ibu) menambah: “...saya dengan suami suka bagi anak-anak pergi ke sekolah, tapi kadang-kadang anak ni sendiri yang tak nak datang, sebab kami sekeluarga ada hari nak ikut ayah mereka masuk hutan untuk kutip rotan..."

Hal tersebut menunjukkan bahawa masalah ponteng merupakan perkara utama yang masih membelenggu anak-anak Orang Asli di Sungai Berua. Kenyataan tersebut juga menunjukkan bahawa segelintir ibu bapa Orang Asli mengharapkan anak mereka untuk hadir ke sekolah, namun sikap muridmurid itu sendiri yang merencatkan keadaan dan proses pembelajaran mereka di sekolah.

\section{Peranan ibu bapa}

Kurangnya kesedaran tentang peri pentingnya pendidikan dalam kalangan ibu bapa murid-murid Orang asli merupakan cabaran yang perlu dihadapi oleh pihak sekolah dan guru-guru SK Sungai Berua. Mereka sangat sukar memberikan kerjasama dan memahami perlunya sesuatu program yang dijalankan oleh pihak sekolah dan kepentingannya. Terdapat ibu bapa murid-murid yang mengharapkan pihak guru dan sekolah untuk membentuk sahsiah dan menguruskan pendidikan anak-anak mereka. Malah, terdapat juga ibu bapa yang tidak menghiraukan keadaan anak-anak mereka sama ada hadir ke sekolah atau sebaliknya. Malah, ada di antara ibu bapa yang mengharapkan anak mereka untuk membantu mencari rezeki untuk kelangsungan hidup keluarga. Terdapat juga ibu bapa dan masyarakat Orang Asli masih tidak berminat dengan pendidikan malah mereka melihat sekolah sebagai suatu tempat untuk menghantar anak-anak mereka untuk bermain dan makan. Zalina (guru PK1) menjelaskan:

“...Tapi apa yang penting kena bermula dari parents dulu lah. Buat perubahan minda, bagi motivasi ke. Sebab setakat ni kehadiran bermasalah sebab parents 
bawak anak keluar masuk hutan. Haaa jadi kita nak bagi macam kesedaran pada parents dulu. Pentingnya pendidikan dan hantar anak ke sekolah..."

Kenyataan tersebut menjelaskan bahawa pihak sekolah secara tidak langsung memainkan peranan yang amat penting sebagai agen yang menjadi acuan untuk membentuk sikap keperibadian murid-murid Orang Asli. Terdapat ibu bapa Orang Asli yang berpandangan bahawa peranan dunia pendidikan dalam mengubah mobiliti sosial mereka serta keberatan menerima pandangan bahawa pendidikan formal boleh membantu mereka memperbaiki keadaan hidup (Hasan Mat Nor, 1998). Kenyataan tersebut juga selari dengan Nur Bahiyah et al. (2013), yang menyatakan terdapat segelintir ibu bapa Orang Asli Sungai Berua yang membiarkan saja anak-anak mereka ponteng sekolah kerana mereka berpendapat bahawa ilmu tidaklah begitu penting. Bagi mereka ilmu yang dipelajari di sekolah hanya membazirkan wang mereka tanpa memberikan keuntungan kepada mereka. Selain itu, terdapat juga para pelajar yang membantu kerja-kerja rumah seperti menjaga adik ketika ibu bapa mereka bekerja.

\begin{abstract}
Ustaz (sekolah) menjelaskan: “...tapi apa yang penting kena bermula dari parents dulu lah. Kena ada perubahan minda, sebab setakat ni kehadiran bermasalah sebab parents bawak anak keluar masuk hutan. Haaa jadi kita nak bagi macam kesedaran pada parents dulu. Pentingnya pendidikan dan hantar anak ke sekolah..."
\end{abstract}

Masalah literasi dalam kalangan anak-anak Orang Asli juga berpunca daripada peranan ibu bapa dan keluarga itu sendiri. Terdapat dalam kalangan ibu bapa anak-anak Orang Asli yang tidak tahu membaca dan mengira seterusnya mereka tidak mampu untuk mengajar kepada anak-anak mereka. Malah, kajian oleh Rosniza et al. (2017) juga mendapati masalah literasi dalam kalangan ibu bapa Orang Asli serta kurangnya kesedaran tentang pentingnya pendidikan menyebabkan anak-anak mereka tidak bermotivasi untuk mengikuti proses pembelajaran di peringkat sekolah.

\title{
Kemudahan bantu mengajar
}

Memandangkan sebahagian besar dari murid sekolah mempunyai masalah menguasai kemahiran 3M sekolah sepatutnya mempunyai guru-guru yang mahir dengan pemulihan. SK Sungai Berua kekurangan guru pemulihan yang benar-benar pakar dalam mengatasi masalah pembelajaran murid. SK Sungai Berua juga memerlukan guru pakar pemulihan yang boleh memantau dan menjalankan program pemulihan secara berkesan. Pengetahuan pemulihan yang guru-guru terima adalah terlalu asas dan umum yang mereka dapati semasa menuntut di maktab perguruan. Mereka mempunyai pengetahuan asas dalam pengajaran pemulihan $3 \mathrm{M}$, tetapi tiada kepakaran praktikal yang khusus secara menyeluruh dalam proses pengajaran anak-anak Orang Asli. Selain itu, SK Sungai Berua juga kekurangan kelengkapan alat bantuan mengajar multimedia seperti capaian sambungan Internet, kemudahan komputer terkini dan jaringan telekomunikasi yang lemah. Kekurangan alat bantuan mengajar berasaskan teknologi menyebabkan murid-murid Orang Asli tidak menerima pendedahan dengan teknologi dengan sepenuhnya. Zalina (PK1) menyatakan:

“...line internet dekat Sungai Berua ni memang teruk. Kita ada jugak Vle Frog KPM sетиa tu, diorang biasa jugak, macam students Tahap 2 biasa jugak masuk ke bilik komputer buat Vle Frog. Tapi masalah kita capaian internet teruk. Sangat terbatas..."

Kenyataan tersebut jelas menunjukkan bahawa terdapat program dan aktiviti berasaskan teknologi multimedia tidak dapat dijalankan akibat kekurangan kelengkapan dan akses internet yang baik. Malah, sekiranya kemudahan dan kelengkapan komputer dalam keadaan baik, murid-murid Orang Asli semakin minat untuk hadir ke sekolah. Hal tersebut selari dengan kajian oleh Rosniza et al. (2017) yang mendapati bahawa penggunaan teknologi dalam pengajaran dapat menarik minat pelajar untuk pergi ke sekolah. Kajiannya juga mendapati penggunaan perisian 'Power Point' ketika sesi pengajaran menarik minat murid-murid Orang Asli untuk meneruskan sesi persekolahan. Murid-murid Orang Asli SK Sungai Berua seharusnya diberikan pendedahan dengan perkembangan pembelajaran secara multimedia agar selari dengan proses pembelajaran murid di sekolah aliran perdana. 


\section{Kesimpulan}

Secara keseluruhannya, tahap pencapaian pendidikan merupakan salah satu kayu ukur untuk mendapatkan kualiti kehidupan yang lebih baik pada masa akan datang. Namun, bagi mencapai impian tersebut, pendidikan merupakan kunci utama yang perlu diberi perhatian serius oleh semua pihak. Kesedaran ibu bapa masyarakat Orang Asli terhadap kepentingan pendidikan anak-anak mereka agar mempunyai masa hadapan yang cerah adalah sangat diperlukan ketika ini. Implikasi hasil kajian ini terhadap persepsi ibu bapa apabila silibus pelajaran sekolah rendah anak-anak Orang Asli di Sekolah Rendah (OA) Sungai Berua telah disesuaikan dengan budaya komuniti setempat seperti muzik dan tarian kebudayaan, seterusnya telah menarik perhatian pihak ibu bapa dan anak-anak mereka terhadap proses pengajaran dan pembelajaran di sekolah tersebut.

Masyarakat Orang Asli merupakan kelompok masyarakat yang mempunyai latar belakang yang amat berbeza dengan masyarakat arus perdana yang lain. Justeru, masyarakat Orang Asli terutamanya anakanak Orang Asli memerlukan silibus kurikulum khas yang mampu untuk membantu mereka mencapai tahap kendiri di dalam perkembangan pendidikan mereka. Anak-anak Orang Asli seharusnya menjadi fokus utama yang perlu diberi perhatian kerana masa depan generasi masyarakat Orang Asli bergantung kepada generasi muda mereka pada hari ini. Pendidikan bukan hanya semata-mata untuk mengenal huruf, membaca dan mengira. Namun pendidikan merupakan kunci utama sebagai bekalan masa hadapan. Pendidikan mampu untuk membawa kelompok keluarga mereka untuk keluar daripada kancah kemiskinan melalui pekerjaan yang baik. Pendidikan juga mampu meningkatkan taraf kesejahteraan dan kualiti hidup mereka dengan adanya peluang pekerjaan yang baik atas kelayakan pendidikan yang dimiliki oleh anak-anak Orang Asli. Manfaat yang diperoleh daripada kualiti pendidikan yang baik diharap dapat membantu mereka meningkatkan taraf hidup agar jurang yang luas tersebut dapat dirapatkan seiring dengan perkembangan masyarakat arus perdana.

\section{Penghargaan}

Penghargaan kepada Geran Kursi Endowmen MPOB-UKM (EP-2019-054 dan EP-2017-061) kerana memberi peluang dan membiayai kerja lapangan serta bantuan dari segi kepakaran para penyelidik dan penerbitan artikel ini. Tidak lupa penghargaan kepada guru-guru Sekolah Kebangsaan (OA) Sungai Berua dan penduduk Kampung Orang Asli Sungai Berua, Kuala Berang Terengganu di atas kerjasama yang diberikan.

\section{Rujukan}

Abdul Jalil Othman, Normarini Norzan, Ghazali Darusalam \& Saedah Siraj. (2011). Cabaran guru program Linus dalam pengajaran dan pembelajaran bahasa. Jurnal Masalah Pendidikan, 34, 37-51.

Ainol Hamidah Ahmad Sarimin \& Saemah Rahman. (2018). Persepsi murid Orang Asli terhadap kurikulum dan relevansi dalam kehidupan. e-Prosiding Persidangan Antarabangsa Sains Sosial dan Kemanusiaan 2018, hlm. 105-124.

Candyrilla Vera Bartholomew. (2017). Hunting of Threatened Wildlife Species by Indigenous People in Kenyir, Terengganu Peninsular Malaysia: Prevalence, Predictors, Perceptions and Practices. Master Thesis, Universiti Malaysia Terengganu.

Celinea Lasan \& Zamri Mahamod. (2018). Pembelajaran timbal balik Bahasa Melayu dalam kalangan murid Peribumi Bidayuh di Sarawak. Jurnal Pendidikan Malaysia, 43(2): 1-15.

Education Council. (2015). National Aboriginal and Torres Strait Islander Education Strategy 2015. Canberra: Education Council.

Hasan Mat Nor. (1998). Warga Pribumi Menghadapi Cabaran Pembangunan. Bangi: Universiti Kebangsaan Malaysia.

Ishak Sin \& Nor Asikin Salleh. (2003). Era globalisasi: Pendidikan dan cabaran. Jurnal Pengurusan dan kepemimpinan, 13. 14-28.

Johari Talib \& Nazri Muslim. (2007). Bagaimana kanak-kanak Orang Asli gagal di sekolah?. Jurnal Pengajian Umum Asia Tenggara, 8(4): 51-76. 
Maszuraini Miswan, Sheela Nair Gopala Nair, Latip Muhammad, Najah Che Ismail, Azman Mohammad \& Ahmad Zhaafar Ismail. (2012). Kajian program Linus: Faktor murid tidak menguasai kemahiran asas literasi dan numerasi. Jurnal Penyelidikan Pendidikan, 13, 46-58.

Mohamad Johdi Salleh. (2009). Kajian terhadap kesedaran pendidikan di kalangan masyarakat Orang Asli. Persidangan Kebangsaan Pendidikan Luar Bandar 2009, Universiti Malaysia Sabah, hlm. 35.

Mohd Muizzuddin Mohd Nor, Mohamad Fauzi Sukimi, Mohd Nasaruddin Mohd Nor. (2018). Kesedaran pendidikan dan minat pelajar Orang Asli suku kaum Jakun di Rompin, Pahang. Malaysian Journal of Society and Space, 14(1), 71-86.

National Collaborating Center for Aboriginal Health. (2017). Education as a Social Determinant of First Nation, Inuit and Metis Health. Prince George British Columbia: National Collaborating Center for Aboriginal Health.

Nazariyah Sani. (2014). Merapatkan jurang literasi murid-murid Orang Asli: Apa cabarannya?. Jurnal Personalia Pelajar, 17, 19-30.

Noorsham Muhamad Din, Zainin Bidin, Isham Ishak, Soon Seng Thah \& Latip Mohammad. (2012). Kajian persekolahan murid Orang Asli. Jurnal Penyelidikan Pendidikan, 13, 1-18.

Norwaliza Abdul Wahab \& Ramlee Mustapha. (2015). Reflections on Pedagogical and Curriculum Implementation at Orang Asli Schools in Pahang. Procedia-Social and Behavioral Sciences, $172,442-448$.

Nur Bahiyah Binti Abdul Wahab,a, Maryati Mohameda, Azman Hassana, Mohd. Najib Haron. (2013). Penerapan Elemen Sekolah Rimba Malaysia Dalam Kalangan Murid Orang Asli. Universiti Tun Hussein Onn Malaysia, 424-432.

Ogburn, W.F. (1964). Culture Lag as Theory and Social Change. In Culture and Social Change. Chicago: The University of Chicago Press. 86-95.

Rosniza Aznie Che Rose, Norhazlinda Saari \& Novel Lyndon. (2017). Kefahaman dan pengalaman literasi dalam kalangan masyarakat Orang Asli Pahang. Journal of Social Sciences and Humanities, 2, 116-124.

Ross, C. E \& Willigen, M.V. (1997). Education and subjective quality of life. Journal of Health and Social Behavior, 38(3), $275-297$.

Siti Masayu Rosliah Abdul Rashid \& Narimah Samat. (2018). Kemiskinan keluarga dan pengaruhnya terhadap tahap pendidikan rendah masyarakat luar bandar: Kajian kes di Jajahan Bachok, Kelantan. Journal of Social Sciences and Humanities, 13(2): 011-023.

Suruhanjaya Hak Asasi Manusia. (2010). Laporan Status Hak Pendidikan Kanak-kanak Orang Asli. Kuala Lumpur: Suruhanjaya Hak Asasi Manusia.

United Nations. (2009). State of the World's Indigenous Peoples. New York: United Nations.

United Nations. (2017). State of the World's Indigenous Peoples: Education. New York: United Nations.

Van den Branden, K. (2015). Sustainable education: Exploiting students' energy for learning as a renewable resource. Sustainability, 7, 5471-5487.

Wahab, N. B. B. A., Mohameda, M., Hassana, A., \& Haronb, M. N. (2013). Penerapan elemen sekolah rimba Malaysia dalam kalangan murid Orang Asli. In 2nd International Seminar on Quality and Affordable Education (ISQAE 2013),organised by Faculty of Education, Universiti Teknologi Malaysia at KSL Hotel \& Resort, Johor Bahru (pp. 424-432).

Wan Afizi Wan Hanafi, Shaharuddin Ahmad \& Noraziah Ali. (2014). Faktor budaya dan persekitaran dalam prestasi pendidikan anak Orang Asli Malaysia: Kajian kes di Kelantan. Malaysian Journal of Society and Space, 10(5), 107 - 122.

Yew, V.W.C., Abd Hair Awang, Sivapalan Selvadurai \& Mohd Yusof Hussain. (2018). Mengukur kesejahteraan Orang Asli. Dalam Pemerkasaan Kesejahteraan Hidup Orang Asli Malaysia. Penerbit Universiti Kebangsaan Malaysia, Bangi, Selangor (hlm. 29-40). 